\title{
有机染料敏化剂分子设计新进展
}

\author{
何俊杰陈舒欣王婷婷曾和平* \\ (华南理工大学化学与化工学院 功能分子研究所 广州 510640)
}

\begin{abstract}
摘要 综述了应用于染料敏化太阳能电池的多吡啶钉配合物、胺类染料、卟啉和酞菁类染料分子设计方面影响其光电 转化效率的因素研究及新进展.

关键词 染料敏化太阳能电池; 敏化剂; 染料; 构效关系
\end{abstract}

\section{Recent Advances of Novel Designs of Dyes for Dye Sensitized Solar Cells}

\author{
He, Junjie Chen, Shuxin Wang, Tingting Zeng, Heping* \\ (Institute of Functional Molecular, School of Chemistry and Chemical Engineering, \\ South China University of Technology, Guangzhou 510640)
}

\begin{abstract}
The operation principle for dye sensitized solar cells and the factors affecting the efficiency are introduced. Recent advances of novel designs of dyes, including ruthenium complexes, amine, porphyrins and phthalocyanines, which are applied in dye sensitized solar cells, are reviewed. In this paper, structure-property relationship of dyes is also discussed.

Keywords dye sensitized solar cell; sensitizer; dye; structure-property relationship
\end{abstract}

自 Gräzel 等 ${ }^{[1]}$ 于 1985 年发明了染料敏化太阳能电 池(DSSCs), 并在 1991 年取得了突破后 ${ }^{[2]}$, 这种太阳能 电池因其生产工艺简单, 原料成本相对于传统硅系太阳 能电池低, 吸引了世界上众多研究者的目光, 成为当前 光伏技术研究领域的热点之一.

经过研究者二十多年的努力, 目前 DSSCs 的光电 转换效率已达到 $11.1 \%{ }^{[3]}$, 虽然低于多晶硅太阳能电池 $15 \% \sim 18 \%{ }^{[4]}$ 的效率，但该项技术依然被认为极有可能 取代硅系太阳能电池, 成为第三代太阳能电池. 世界上 已有 G24 创新公司(G24 Innovations) ${ }^{[5]}$, 日本的 SONY ${ }^{[6]}$, SHARP, Dyesol ${ }^{[7]}$ 和 Konarka ${ }^{[8]}$ 等多家公司进行着 DSSCs 的生产和应用研究, 爱尔兰的 SolarPrint 公司近日也宣 布了他们商业化生产 DSSCs 的计划 ${ }^{[9]}$. 国内也相继成立 了大连七色光太阳能科技开发有限公司和河北汉光重 工有限责任公司进行染料敏化太阳能电池相关产品的 研发和生产.
为了提高 $\mathrm{DSSCs}$ 光电转换效率及生产工艺上进一 步提高改进, 除了在 DSSCs 器件 ${ }^{[10]}$ 方面做深入研究外, 众多研究者也将精力集中在开发具有更宽光谱响应范 围和高摩尔消光系数的敏化剂上. 作为敏化剂的染料选 择范围很广, 目前研究较多的敏化剂有以 N3 $\left[\mathrm{RuL}_{2}-\right.$ $(\mathrm{NCS})_{2}, \mathrm{~L}=2,2^{\prime}$-bipyridine-4,4'-dicarboxylic acid], N719 $\left[\mathrm{L}_{2}(\mathrm{NCS})_{2}: 2 \mathrm{TBA}, \quad \mathrm{L}=2,2^{\prime}\right.$-bipyridyl-4,4'-dicarboxylic acid] 和 N749[即黑染料, RuL(NCS) $)_{3}: 3 \mathrm{TBA}, \mathrm{L}=2,2^{\prime}: 6^{\prime}, 2^{\prime \prime}-$ terpyridine-4,4',4"-tricarboxylic acid]为代表的多吡啶钉 配合物, 胺类染料以及具有大 $\pi$ 体系的卟啉和唒菁类化 合物等，另外还包括无机半导体纳米颗粒一一量子点.

国内研究者曾分别对不同类型的染料做过介

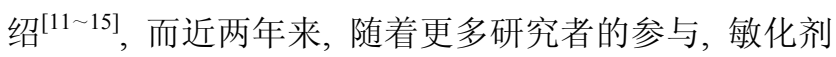
的研究有了可喜的新发展和新突破, 对各种染料的结构 设计和修饰手段也变得逐渐系统化. 本文对 DSSCs 研 究中近年来多吡啶钉配合物，无金属染料以及卟啉和酞

\footnotetext{
*E-mail: hpzeng@scut.edu.cn

Received May 14, 2011; revised September 14, 2011; accepted November 1, 2011.

Project supported by the National Natural Science Foundation of China (No. 21071054), the Science and Technology Planning Project of Guangdong Province (Nos. 2008B010800030, 2009B091300045) and the Fundamental Research Funds for the Central Universities of South China University of Technology (No. 2009ZM0179).

国家自然科学基金(No. 21071054)、广东省科技项目(Nos. 2008B010800030，2009B091300045)和华南理工大学中央高校基本科研业务费(No. 2009ZM0179)资助项目.
} 
菁四类敏化剂分子结构设计研究的最新发展状况进行 了综述, 并分别对各类染料的结构设计和修饰手段进行 了归纳, 最后对 DSSCs 敏化剂在未来的研究和应用做 了展望.

\section{1 影响光电转换效率的因素}

DSSCs 由光阳极、敏化剂、电解质和对电极构成(图 1).

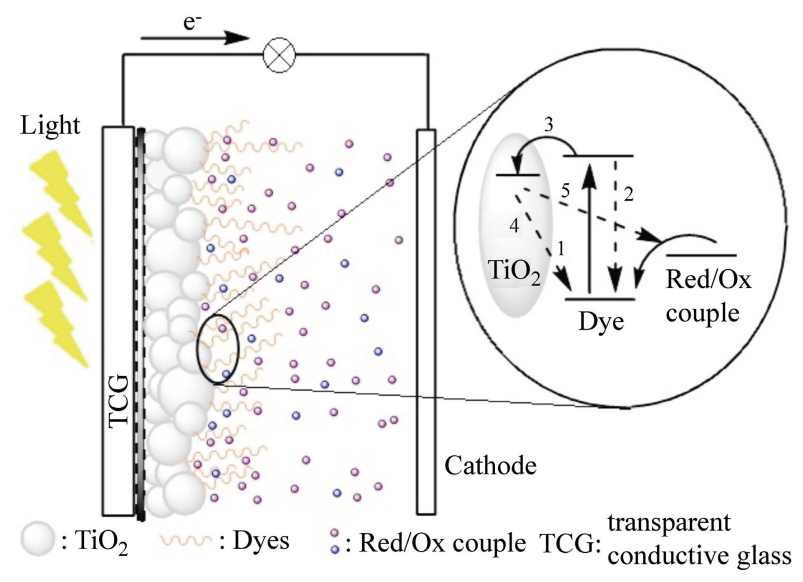

图 1 DSSCs 工作原理示意图

Figure 1 Illustration of the operation principle for DSSCs

光阳极是 DSSCs 的核心部分, 起到吸收太阳光并 使光生激子分离形成电子空穴对的作用. 它是先在 $\mathrm{FTO}$ (掺氟 $\mathrm{SnO}_{2}$ ) 透明导电玻璃上烧结一层半导体氧化物 薄膜(常见的主要有 $\mathrm{TiO}_{2}, \mathrm{ZnO}$ 和 $\mathrm{SnO}_{2}$ 等), 再在这类半 导体薄膜表面吸附一层窄带隙的敏化剂, 用于吸收穿过 透明导电玻璃的太阳光, 产生激子, 激子在半导体与敏 化剂界面处分离, 电子注入到半导体导带, 同时在敏化 剂价带形成空穴, 该空穴被电解质还原. 注入到半导体 的电子被导电玻璃收集, 最后再从外电路由阴极回到电 解质. 就这样在外电路形成源源不断的电流.

很显然, 在 DSSCs 光电转换过程中, 导致其效率降 低的过程是(如图 1 所示): 光生激子通过辐射跃迁回到 基态(2); 注入半导体导带的电子与敏化剂空穴发生复 合(4); 注入半导体导带的电子被电解质中氧化还原电 对的氧化态所捕获(5). 抑制这几个过程也是提高电池 转换效率的有效途径.

主要有以下几项指标来衡量 DSSCs 的性能:

(1)总转换效率: $\eta=V_{\mathrm{oc}} \cdot J_{\mathrm{sc}} \cdot \mathrm{FF} / I_{\mathrm{s}}^{[16]}$

式中 $V_{\mathrm{oc}}$ 为开路电压, $J_{\mathrm{sc}}$ 为短路电流密度, $\mathrm{FF}$ 为填充因 子, $I_{\mathrm{s}}$ 为入射光密度. 其中 $V_{\mathrm{oc}}$ 和 $J_{\mathrm{sc}}$ 是实验测量值, 而 $I_{\mathrm{s}}$ 则可按实验需求设定. $\mathrm{FF}$ 由电池最大输出能量 $P_{\text {max }}$ 除以 开路电压与短路电流之积得到, 即 $\mathrm{FF}=P_{\max } /\left(V_{\mathrm{oc}} \bullet J_{\mathrm{sc}}\right)$.

影响 $V_{\mathrm{oc}}$ 的因素很多, 目前已经清楚的两个因素分
别是: (a)半导体费米能级与空穴传输材料氧化电势之 差; (b)注入 $\mathrm{TiO}_{2}$ 导带的电子与电解质的复合会导致 $V_{\mathrm{oc}}$ 的减小 ${ }^{[17]}$.

对 $J_{\mathrm{sc}}$ 的主要影响因素有: (a)敏化剂的光响应范围; (b)敏化剂的激发系数; (c)半导体表面敏化剂的覆载 量 ${ }^{[16,18]} ;$ (d)半导体薄膜的电阻率 ${ }^{[19]}$.

(2)单色光光电转换效率:

$\operatorname{IPCE}(\lambda)=\operatorname{LHE}(\lambda) \bullet \varphi_{\text {inj }} \bullet \eta_{\text {coll }}{ }^{[16]}$

$\operatorname{LHE}(\lambda)$ 为入射单色光波长, $\varphi_{\text {inj }}$ 为电子自激发态染料注 入半导体导带的量子产率, $\eta_{\mathrm{coll}}$ 为电子收集效率.

\section{2 敏化剂新结构}

敏化剂在 DSSCs 中起着捕获太阳光的作用，该部 分能否最大限度地吸收太阳光直接决定了光电池可能 获得的最大能量转换效率. 按照一定的策略对染料分子 结构进行精心设计是开发高效染料的先决条件.

为了获得高效率的敏化剂染料, 染料分子结构设计 需遵循以下 6 个基本原则: (1)染料的吸收光谱应该覆盖 紫外可见光区和近红外区域( $300 \sim 2500 \mathrm{~nm})$, 激发系数 必须尽可能高, 以便于通过使用更薄的 $\mathrm{TiO}_{2}$ 膜获得高 效的光捕获性能; (2)为了使得电子能够有效地注入阳 极, 染料的最低末占轨道(LUMO) 应该靠近键和基 团 ${ }^{[20]}$ (一般是羧酸或磷酸基团), 并且, 其能级应高于半 导体的导带; (3)染料的最高占有轨道(HOMO)应在电解 质中作为空穴传输材料的氧化电势之下, 以使得染料在 被氧化后可以迅速恢复; (4)为了抑制已注入半导体导带 的电子与氧化态染料的复合, 染料上的正电荷应远离 $\mathrm{TiO}_{2}$ 表面; (5)染料外围应该疏水, 从而减少光阳极与电 解质的直接接触，抑制染料从 $\mathrm{TiO}_{2}$ 表面因水解导致的 脱落, 延长电池寿命; (6)避免染料在 $\mathrm{TiO}_{2}$ 表面因发生堆 积而导致的由激发态到基态的非辐射跃迁 ${ }^{[20]}$.

\section{1 钉染料结构修饰}

在 DSSCs 研究早期以多吡啶钓配合物染料作为敏 化剂 ${ }^{[1]}$, 至今该类染料依然保持着 DSSCs 最高的转换效 率. 对这类染料结构修饰的研究集中在配体结构的修饰 上.

图 2 所示为常被作为比较标准的 AM1.5 太阳光谱 图及保持着 DSSCs 光电转换效率最高纪录的 N749 染料 的 IPCE (incident photon to current conversion efficiency) 随波长的变化情况 ${ }^{[21]}$. 从图中可以看出, N749 在 800 $\mathrm{nm}$ 以下的可见光区都保持了 $50 \%$ 以上的 IPCE 值, 因而 获得了比较满意的光电转换效率.

\subsection{1 提高摩尔消光系数}

提高染料的摩尔消光系数可以在保持染料负载量 
不变的情况下降低 $\mathrm{TiO}_{2}$ 薄膜的厚度, 从而减小暗电流, 提高 $V_{\mathrm{oc}}$. 类似于 $\mathrm{N} 749$, 虽然这类多吡啶钓配合物染料 具有很宽的吸收光谱, 但这类染料的摩尔消光系数属中 等, 并不强. 为增强该类染料的摩尔消光系数, 提高空 穴的传输性能, Chen 等 ${ }^{[22]}$ 在配体上引入起到空穴传输 作用的噻吩官能团, 制得了 $\mathrm{Ru}-1$ 和 Ru-2 等染料, 在相

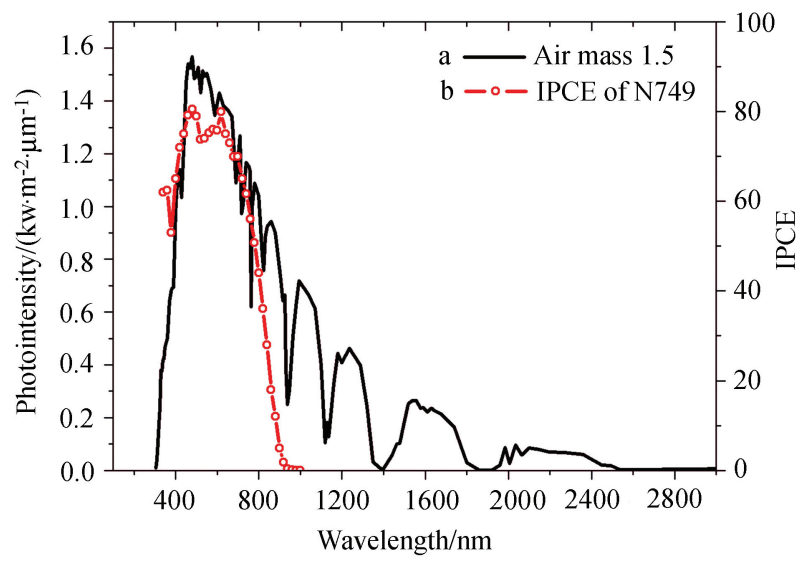

图 2 (a) AM1.5 太阳光谱分布和(b) N749 染料的 IPCE 随波长 的变化

Figure 2 (a) Distribution of AM1.5 global spectrum and (b) incident photon to current conversion efficiency as a function of the wavelength for N749
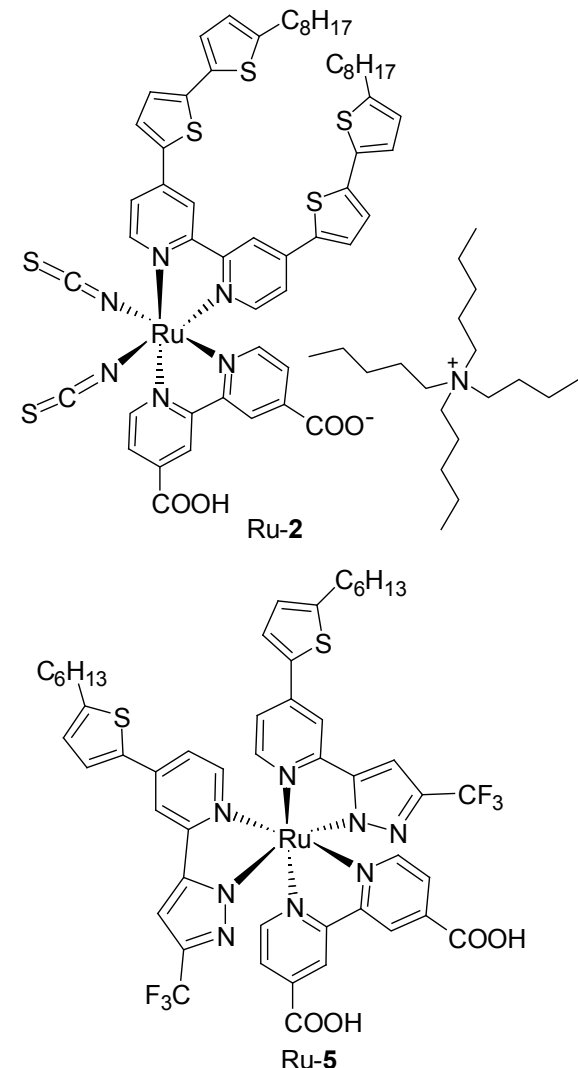

同条件下对应器件的光电转换效率皆高于 N3 染料, 这 主要归因于摩尔消光系数增强所致的光电流密度提高. 类似结构的 Ru-3 也被应用于固体染料敏化太阳能电池， 相对于不带噻吩基团但结构相似的 $\mathrm{Ru}-\mathbf{4}$, 光电转化效 率提高了 $55 \%{ }^{[23]}$. 另外, 无硫氰根 Ru-5 中, 烷基噻吩官 能团的引进，也使得染料在 $400 \sim 600 \mathrm{~nm}$ 区间内摩尔消 光系数得到很大的提高, 以其制备的光电池短路电流密 度和开路电压都增大，效率优于 $N 719^{[24]}$. 还有 Ru-6 染 料，该染料与 $\mathrm{Ru}-4$ 不同之处是把 $\mathrm{Ru}-4$ 的两个正壬烷基 团替换为已烷氧基团，该染料在短波区域的摩尔消光系 数获得了很大的提升 ${ }^{[25]}$. 如果将烷氧基氧原子对应位 置用硫原子替换, 所得的 TG6 虽然与 Ru-6 染料的吸收 光谱相近，但会导致开路电压下降，作者认为这是由于 染料该位置不同原子与碘发生束缚作用的强弱不同所 致 ${ }^{[17 b]}$.

利用羧基等基团附着在 $\mathrm{TiO}_{2}$ 表面的染料易于在水 的作用下脱落, 缩短了电池的使用寿命, 通过在染料上 引入憎水基团制得 Ru-4 染料，该染料制作的 DSSCs 可 以长时间在加热条件下保持稳定的转换效率 ${ }^{[26]}$. 另外 引入的长链烷烃形成的交联结构也抑制了电解质与 $\mathrm{TiO}_{2}$ 的接触, 使得过程 5 的发生受到抑制.

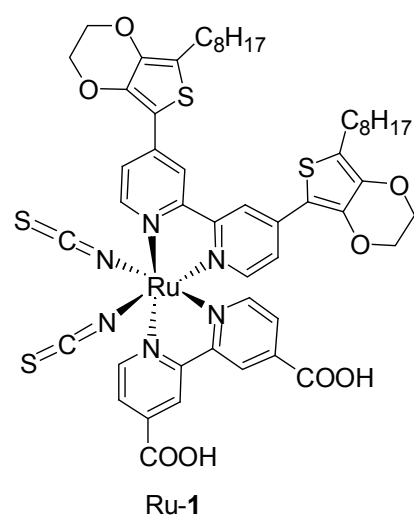

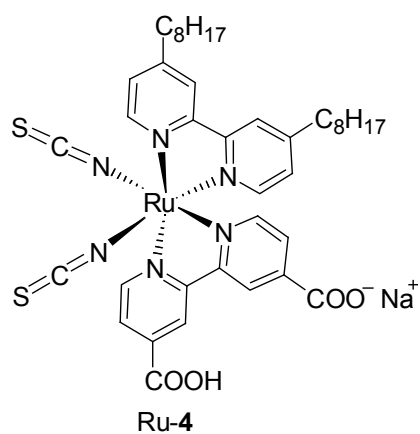

图 3 含有空穴传输官能团的钉染料

Figure 3 Ruthenium complexes with hole-transport moieties 


\section{1 .2 推拉结构钉配合物}

在图 1 中, 过程 4 代表注入 $\mathrm{TiO}_{2}$ 导带电子与染料空 穴的复合过程, 使染料受激发的正电荷远离 $\mathrm{TiO}_{2}$ 表面 可以大为减缓该复合过程的速率. 在联吡啶配体上引入 具有推电子效应的三苯胺官能团制得的染料 Ru-7 的电 荷分离态寿命延长至 $0.7 \mathrm{~s}$, 通过半经验计算发现该染料 的电荷中心与 $\mathrm{TiO}_{2}$ 表面的距离相对于 N719 增加了 4 $\AA^{[27]}$. 类似的具有三苯胺给电子基团的吡啶钉配合物还 有王科志等 ${ }^{[28]}$ 最近报道的 $\mathrm{Ru}(\mathrm{Hipdpa})$ 染料, 相同条件 下, 该染料与 N3 染料表现相当. Thelakkat 等 ${ }^{[29]}$ 所合成 的含有三苯胺给电子基团的 Ru-8 在相同条件下制得的 固体染料敏化太阳能电池获得了比使用 N719 时高出两 倍以上的光电转换效率. 这也证实了在钉染料上引进三 苯胺基团对于其在固体染料敏化太阳能电池当中的应 用也是有利的.

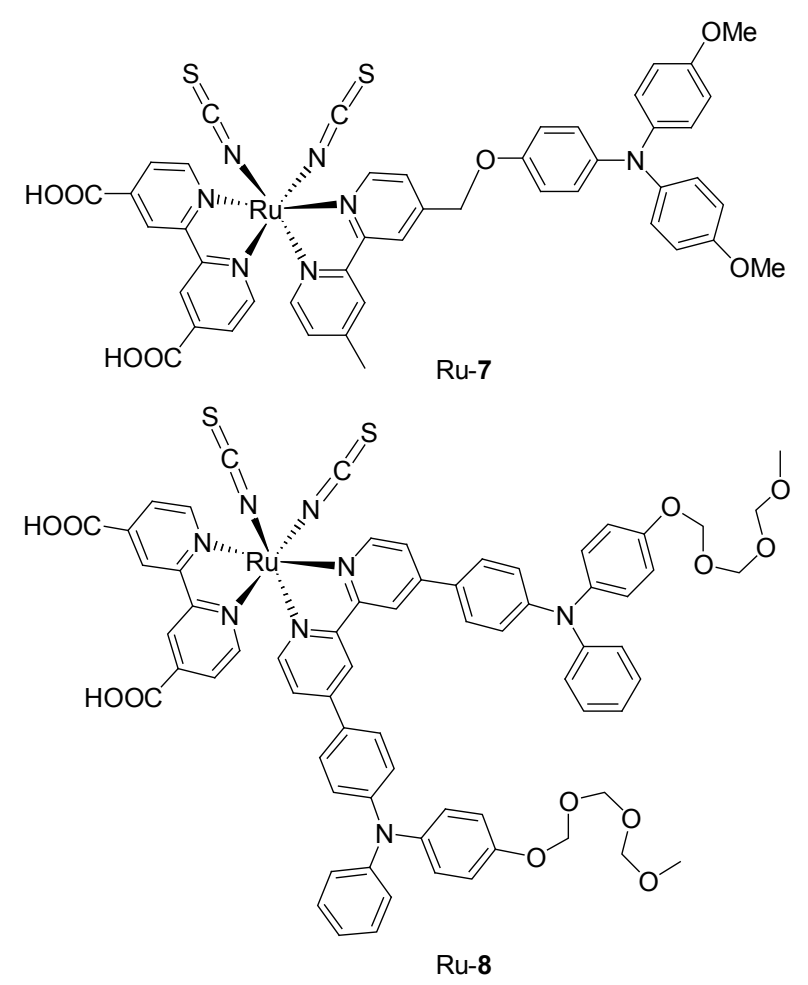

图 4 具有推拉结构的钉染料

Figure 4 Ruthenium complexes of Push-Pull sructure

\subsection{3 新型配体钉染料}

用于 DSSCs 的钉配合物一般是二联吡啶及硫氰根 的配合物, 而不同类型配体对配合物的光电性能有很大 的影响 ${ }^{[30]}$, 采用新型配体是探索性能更加优异钉染料 的一个新兴研究方向.

2007 年 Koten 等 ${ }^{[31]}$ 首先只采用三联吡啶作配体, 未 使用硫氰根, 获得与 N719 效率相当的钉配合物 Ru-9. Grätzel 等 ${ }^{[32]}$ 于 2009 年制备了 $\mathrm{Ru}-10$, 并用 TD-DFT 方 法进行了深入的理论计算研究. 和 N719 相比, Ru-10 在
$490 \mathrm{~nm}$ 处增加了一个吸收带, 并且整个吸收光谱的摩 尔消光系数都有明显的提高, 最终采用丝网印刷制作的 光阳极获得 $10 \%$ 的光电效率. Ru-11 则是使用了 $\mathrm{N}$-杂环 卡宾作为配体代替二联吡啶，该染料同样是由于摩尔消 光系数的明显提高而获得高达 $20 \mathrm{~mA} \cdot \mathrm{cm}^{-2}$ 的短路电流 密度 $(J)^{[33]}$. 另外, 上文提到的 Ru-5 也采用了无硫氰根 的结构, 使用二联吡啶和 2 -吡啶基吡唑作为配体，同等 条件下, 无论短路电流还是开路电压都较 N719 高 ${ }^{[24]}$.

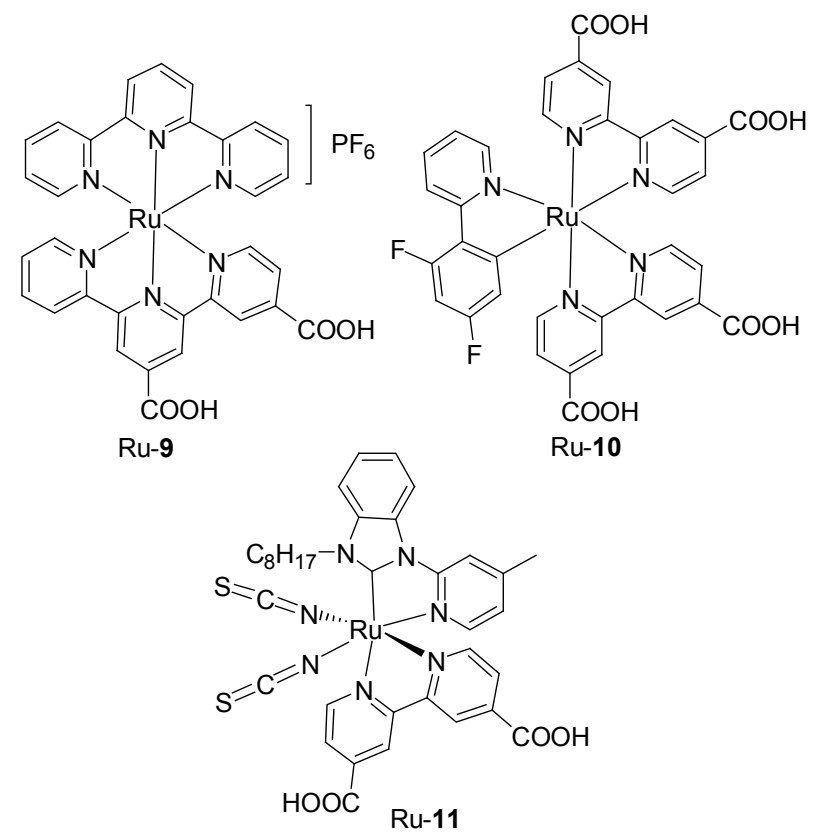

图 5 含不同类型配体的钉染料

Figure 5 Ru-complexes with various ligands

这类采取无硫氰根配位的新结构来对钉染料的光 电性能进行调节的研究, 目前并不多, 构效关系还不清 楚, 值得深入探索.

\section{2 纯有机染料}

由于多吡啶钓类染料的合成及纯化都极为麻烦，且 钉属于贵重的稀有金属, 这使得研究者将目光投向具有 制备成本低, 吸收光谱和光化学性质易于通过合理的结 构设计而调节等特点的无金属有机染料, 目前, 这类染 料中研究的热点是胺类衍生物.

1996 年 Grätzel 等 ${ }^{[34]}$ 发现含胺给电子官能团的香豆 素类衍生物 C343 (Coumarin 343) 能将激发电子以 $5 \times$ $10^{12} \mathrm{~s}^{-1}$ 的速度迅速注入 $\mathrm{TiO}_{2}$ 的导带, 但该化合物却因 为光响应范围较窄, 光电转换效率低. 5 年后的 2001 年, Arakawa 等 ${ }^{[35]}$ 对 C343 进行了结构修饰, 通过增加双键 延长共轭体系，并使用氰基乙酸做受体官能团，使吸收 光谱大大拓宽, 并获得了 $5.6 \%$ 的光电转换效率. 2003 年 该课题组又在之前工作的基础上合成了 $N, N$-二甲基胺 为给体的 NKX-2569 [2-cyano-7,7-bis(4-dimethylamino- 
phenyl)hepta-2,4,6-trienoic acid], 获得了 $6.8 \%$ 的光电转 换效率, 实现了胺类染料性能的一次突破 ${ }^{[6]}$.

这类染料都具有鲜明的 $D-\pi-A$ 结构, 其中 D 代表给 体(常为富电子的胺官能团), $\mathrm{A}$ 代表受体 (通常为吸电子 基团, 如羧酸和氰基丙烯酸等), 两部分通过共轭的 $\pi$ 桥 连接, 如图 6. 一般而言, 这类具有较高光电转换效率 的 D- $\pi$-A 型染料当中, 其 $\mathrm{HOMO}$ 集中在给体部分, LUMO 在受体部分, 因受体与 $\mathrm{TiO}_{2}$ 直接连接, 这使得激 发电子能顺利的自受体注入 $\mathrm{TiO}_{2}$ 的导带, 当电子注入 $\mathrm{TiO}_{2}$ 后, 空穴位于远离 $\mathrm{TiO}_{2}$ 表面的给体一端, 使得电解 质中的氧化还原电对更容易接近该空穴部分, 并很快将 氧化态染料还原, 最终抑制了注入电子与染料空穴的复 合(4).

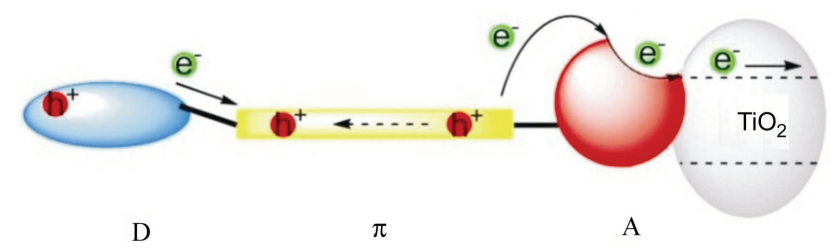

图 $6 \mathrm{D}-\pi-\mathrm{A}$ 型染料结构

Figure 6 Metal-free dyes with D- $\pi$-A structure

目前已经对这种结构的染料进行了大量的结构修 饰研究, 并且取得了令人激动的进展. 这些研究主要集 中在对给体和 $\pi$ 桥部分的修饰, 而受体部分的种类还局 限于腈基丙烯酸和罗丹明-3-乙酸等, 由于以其他官能 团作受体的研究并不多, 故在此不将含这两种受体的染 料作对比讨论. 因篇幅所限, 笔者只选取了该类染料中 一些性能较突出的化合物, 按照对给体和 $\pi$ 桥的不同修 饰方式对性能的影响进行总结和分析.

\section{2 .1 拓宽吸收光谱}

有机染料虽然具有消光系数高的优点, 但是吸收谱 带却较钓染料窄得多, 因而拓宽有机染料的光谱范围是 有机染料研究的重点. 在表 1 的第 $1 \sim 3$ 组的结构比较中 可以发现, 在给体上引入富电子的推电子基团烷基和烷 氧基可获得转换效率的提高. 这主要是因为推电子基团 的引入可以使得分子 HOMO 能级升高, 使得能隙变窄 ( $\Delta E$ 减小), 最大吸收光谱向红光方向移动, 这提高了短 路电流密度. 另外, 烷氧基也抑制了电介质中 $\mathrm{I}^{3-}$ 与 $\mathrm{TiO}_{2}$ 中注入电子的复合过程, 提高了开路电压 ${ }^{[37 b, 38 b]}$.

根据经验, 增加分子的共轭体系可以获得更宽的光 谱响应范围, 如表 1 中第 4 7 组分子, 这几组分子通过 增加芳环或双键实现延长共轭体系, 都获得了光电转换 效率的极大提高. 最近关于第 7 组两个分子的对比研究 发现, 两个噻吩并噻吩之间双键的引入不仅增加了共轭 链长度, 更重要的是双键能减小两个官能团间的二面 角, 使得电子能够有效迁移 ${ }^{[22]}$. 但很不幸, 问题却还没
这么简单，从第 8 组开始到第 11 组却是延长了共轭体系 的分子表现较差. 8,9 这两组是由于两个双键会发生光 异构化反应，导致能量的损失. 第 10 组中, 研究者 ${ }^{[33 a]}$ 认为 $\mathrm{a}$ 结构中双键的增加导致了氧化电势的降低, 这不 利于激发子的有效分离.

\subsection{2 抑制分子堆积}

具有大共轭体系的分子还会在 $\mathrm{TiO}_{2}$ 表面发生堆积, 这种堆积将导致电解质氧化还原电对向对电极的扩散 受阻, 并会与注入 $\mathrm{TiO}_{2}$ 导带的电子复合, 导致开路电压 损失. Gräzel 等开发的二甲基芴胺系列染料(表 1 , 第 5 , $8,9,10$ 组)的目的也在于抑制分子堆积所产生的不利影 响. Wang 等 ${ }^{[46]}$ 发现在使用芳环延长共轭体系时, 在芳 环上引入烷基可以有效抑制堆积的发生(表 1 , 第 12 组). 该研究也发现在延长 $\pi$ 桥时会因 LUMO 能级降低导致 激发电子注入 $\mathrm{TiO}_{2}$ 的效率下降. 目前通过在分子上引 入长链烷基提高溶解度增加分子的可操作性, 以及抑制 堆积发生的设计策略被广泛使用. 但值得注意的是第 13 组中的两个分子, Chen 等 ${ }^{[47]}$ 发现, 引入烷基也会破坏 芳环的共轭结构而导致光谱响应范围的缩小致使效率 降低. 这也说明，在这类二甲基芴胺作为给体的染料中, 分子堆积作用可能并非影响效率提高的主要因素.

\subsection{3 采用新型 $\pi$ 桥}

就在研究者们发现增加共轭体系会导致两难困境 的时候, 2008 年, Chou 等 ${ }^{[396]}$ 的研究非常值得关注. 他们 在三苯胺和氧基丙烯酸之间以 3,4-亚乙二氧基噻吩作为 $\pi$ 桥得到了结构简单的有机染料, 虽然该染料在紫外区 吸收很弱，最大吸收在可见光区，但在相同条件下转换 效率也接近于 N719 而达到 7.3\%, 原因在于太阳光在紫 外光区分布少, 并且该部分是 $\mathrm{TiO}_{2}$ 吸收范围之内. 不引 入 3,4-亚乙二氧基的化合物效率只有 5.2\%. 研究者认为 这是因为这种结构更加有利于激发电子分离为自由电 子和空穴. 这开启了对该类结构染料的修饰研究.

王鹏组 ${ }^{[49]}$ 于次年合成了 $\mathrm{C} 217$ [3-\{2-\{2-\{4-[N,N-bis(4-hexyloxyphenyl)amino]phenyl $\}-3,4$-(ethylenedioxy)-thiophene-5-yl\}thieno[3,2-b] thiophen-5-yl\}-2-cyanoacrylic acid]染料, 该染料也使用 3,4-亚乙二氧基噻吩与给体三 苯胺键连, 提高 $\mathrm{HOMO}$ 能级, 噻吩并噻吩与受体氰基丙 烯酸连接获得更适合的 LUMO, 该染料获得了 $9.8 \%$ 的 光电转换效率, 这和 N3 染料相当. 他们还发现, 使用 3,4-亚乙二氧基噻吩与三苯胺键连时, 苯环与它之间的 扭转角很小, 这有利于给受体之间电子的相互影响. 陈 军等 ${ }^{[50]}$ 最近研究了 3,4-亚丙-1,3-二氧基噻吩桥取代基长 短对染料性能的影响, 也得到相同条件下性能高于 N3 染料的 OR3 [E-2-cyano-3-(8'-(4-(diphenylamino)phenyl)3,3,3',3'-tetrapropyl-3,3',4,4'-tetrahydro-2H,2'H-6,6'-bithie- 
表 1 不同结构修饰手段对染料性能的影响

Table 1 The impact of different means of structural modification on dye performance

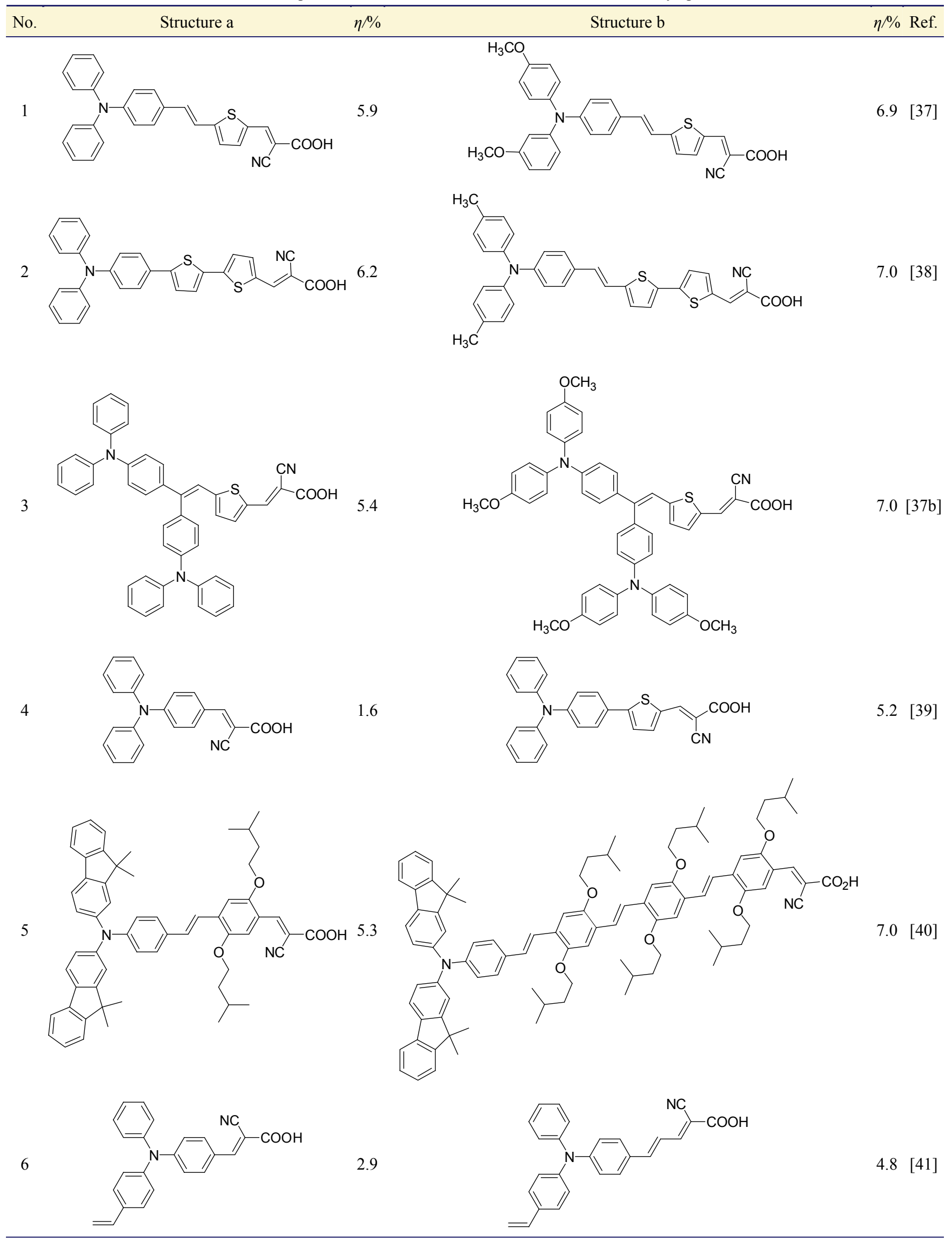


有机化学

综述与进展

续表

No.

Structure a

$\eta / \%$

Structure b

$\eta / \%$ Ref.

7
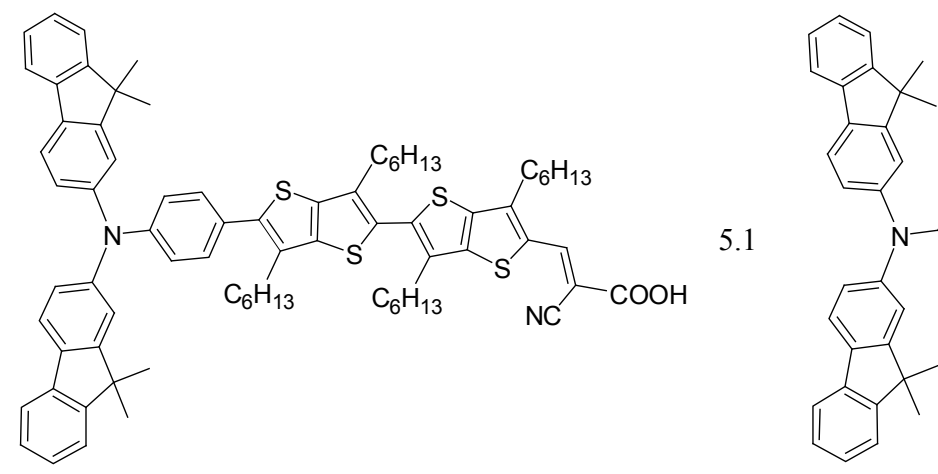

8

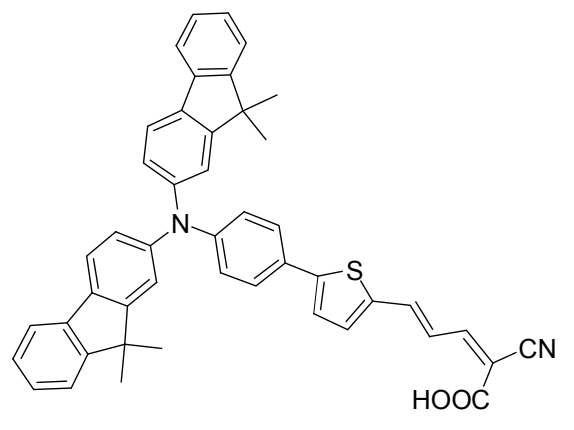

5.1

$7.2[43]$

9

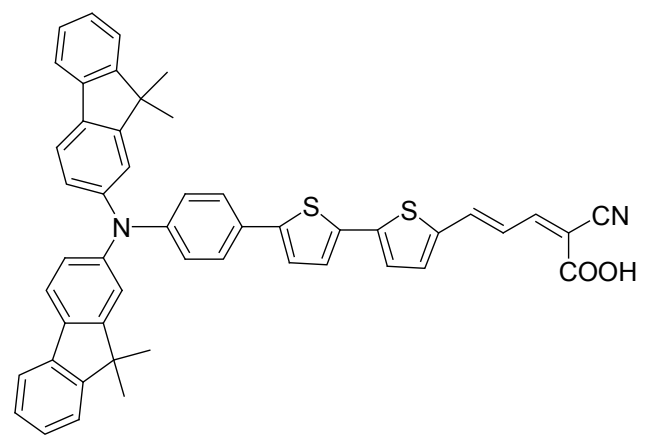

10

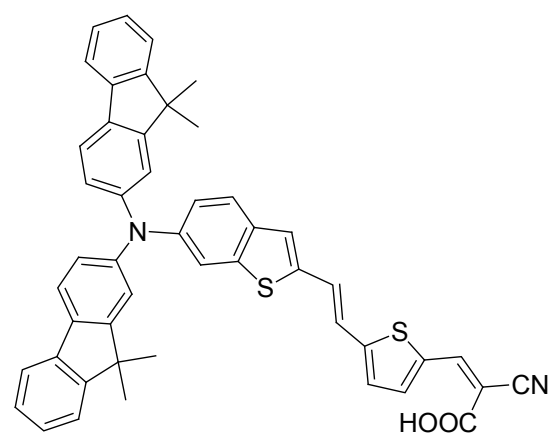

11

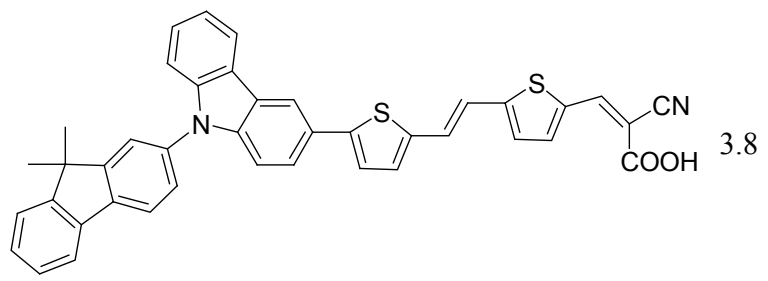

5.5
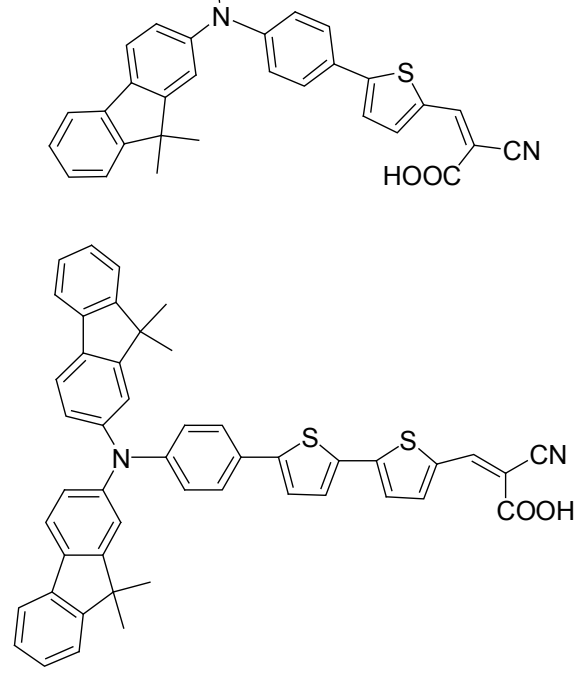

8.0 [43]

7.4 [44]

5.2 [45]

478

http://sioc-journal.cn/

๑ 2012 Chinese Chemical Society \& SIOC, CAS

Chin. J. Org. Chem. 2012, 32, 472 485 


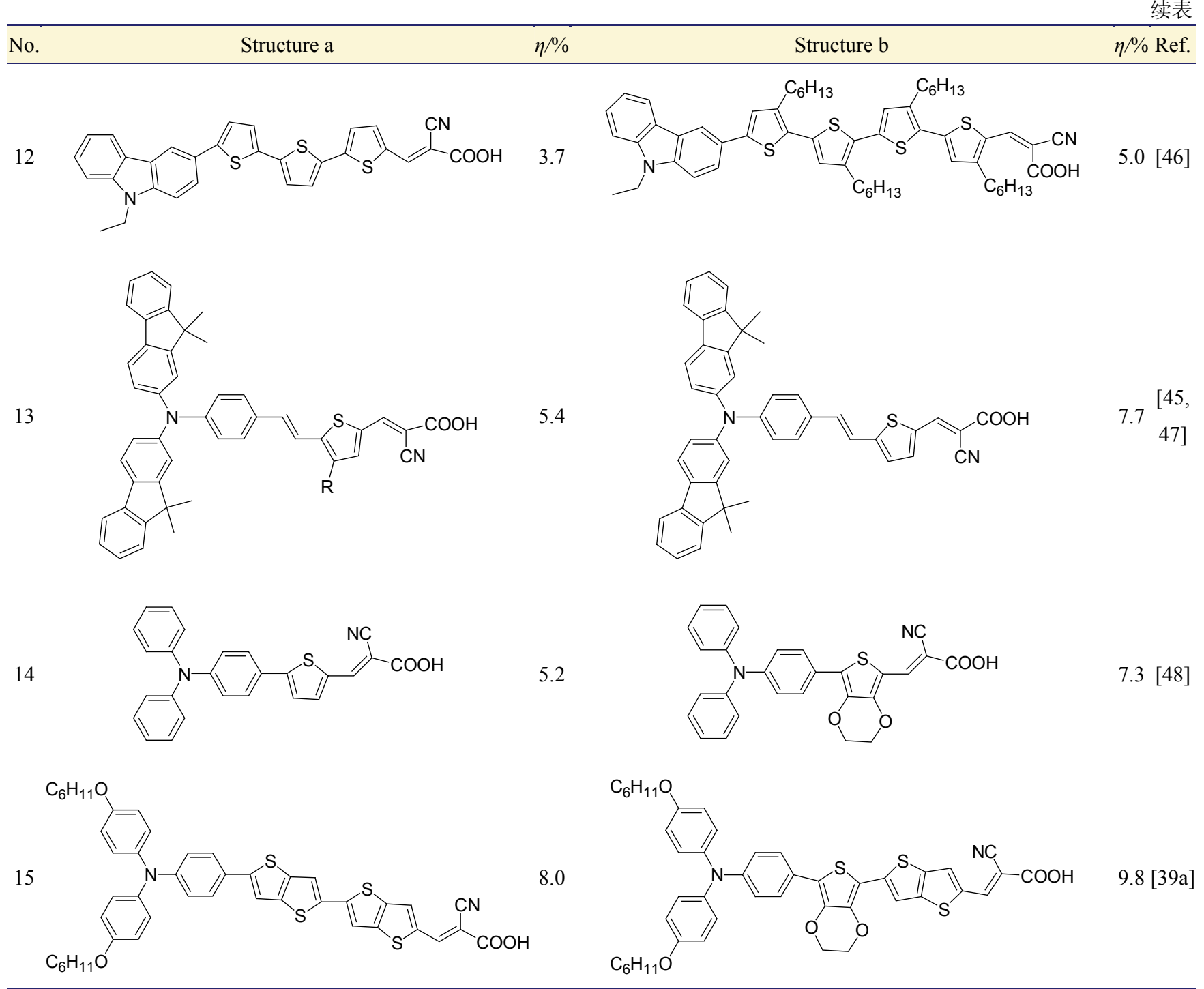

no[3,4-b][1,4]dioxepin-8-yl)acrylic acid]染料. 可见, 这 类具有简单结构的三苯胺染料同样能获得令人满意的 效果. 关于使用 3,4-亚乙二氧基噻吩作为 $\pi$ 桥的设计依 然被其他类型染料所采用, 值得进一步深入研 究 $^{[51]}$.

在精心考虑了各种影响因素之后, 王鹏等 ${ }^{[52]}$ 去年 设计并合成了 C219 染料(图 7), 取得了无金属有机染料 性能的重大突破. 在使用离子液体作为电解质时, 性能 甚至超过钓染料 $\mathrm{Ru}-4$, 最佳效率达到 $10.0 \% \sim 10.3 \%$. 该分子在给体上引入了有推电子作用的烷氧基 ${ }^{[52]}$, 也 采用了 3,4-亚乙二氧基噻吩与给体相连, 另外使用 DTS (dihexyl-substituted dithienosilole)与受体键联的策略也 使得 LUMO 能级更合适, 硅原子上的两条烷基支链可 在不影响共平面性的基础上抑制堆积的发生. 最近具有 相似结构的分子 C220 [2-cyano-3-\{6-\{4-[N,N-bis(4-hexyloxyphenyl)amino]phenyl $\}-4,4$-didodecyl- $4 H$-cyclopenta[2,1-b:3,4- $b^{\prime}$ ]dithiophene-2-yl\}acrylic acid]在固态染
料敏化太阳能电池中的转换效率也首次超过了钉染料 达到 $6.08 \%{ }^{[53]}$.

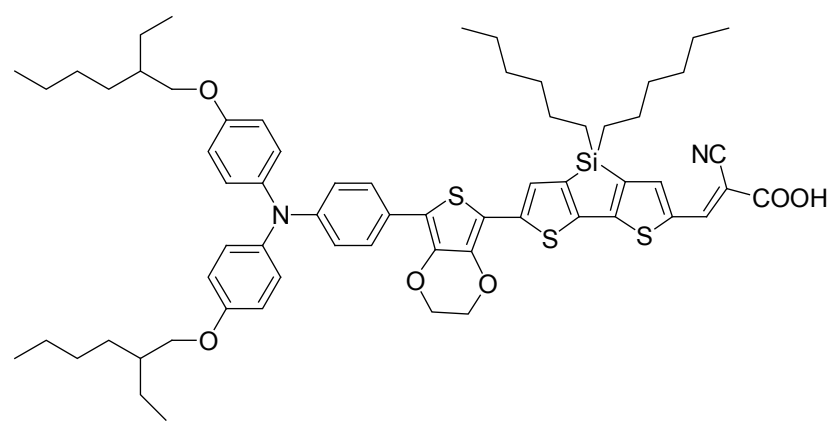

图 7 目前最高效率的非金属染料 C219

Figure 7 The most efficient metal-free dye C219

另外，具有双给体的染料分子也有不少研

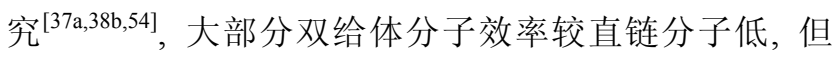
Grätzel 等 ${ }^{[54]}$ 也发现, 用含支链结构的染料所制得的电 
池的性能稳定性要优于直链型染料.

\section{3 卟啉和酞菁类染料}

以上提及的两类染料的吸收光谱大多都在 $600 \mathrm{~nm}$ 以上便呈现明显下降趋势, 这使得太阳光谱中最大光子 流所在的近红外部分不能被有效吸收转换. 卟啉在 $400 \sim 450 \mathrm{~nm}$ 处有吸收很强的 Soret 带, 在 $500 \sim 650 \mathrm{~nm}$ 处具有中等吸收强度的 $Q$ 带. 酞菁在 $600 \sim 700 \mathrm{~nm}$ 范围 的 $\mathrm{Q}$ 带吸收最强, 可以与以上两类染料通过共敏化 $\mathrm{TiO}_{2}$, 起到到吸收光谱互补的作用, 从而拓宽光阳极的 光谱响应范围. 卟啉和唒菁都具有很高的摩尔消光系 数, 这也是制备高效染料所期望的性质之一. 但由于两 者都具有很大的共轭结构, 这使得分子间容易发生有害 的堆积作用, 另外吸收谱带过于狭窄, 能覆盖太阳光谱 中很小的范围是限制两者捕光能力的一个重要因素. 然 而，近年来通过对这两类分子结构进行修饰以后制得的 染料在染料敏化太阳能电池中的表现都大为改善, 尤其 是卟啉类染料已取得了突破性的进展.

\subsection{1卟啉}

卟啉化合物广泛存在于自然界, 种类很多. 在植物 叶绿素进行光合作用时, 卟啉扮演着捕获光能并迅速将 其转化为化学能的重要角色. 早在 1993 年, Gräzel 小 组 ${ }^{[55]}$ 就使用吓啉衍生物为染料制作太阳能电池, 开创 了以卟啉为敏化剂制作 DSSCs 的先河.

早期开展了对称卟啉染料在 DSSCs 中应用的研究, 如四羧酸苯基取代卟啉 $(\mathrm{Zn}-1)^{[56]}$. 一方面的原因在于对 称结构的卟啉较不对称卟啉更容易合成. 然而 Zn-1 的
几个羧基是在同一个平面上, 不能都与 $\mathrm{TiO}_{2}$ 表面相连, 这使得电子注入效率下降. 若羧基在苯环的间位则可以 使得整个分子平躺着吸附在 $\mathrm{TiO}_{2}$ 表面, 提高 $\mathrm{IPCE}^{[566]}$. 按照这个设计 Lee 等 ${ }^{[57]}$ 也将两个羧基置于间位，获得了 在同等条件下与 N719 相当的吓啉染料 Zn-4 (图 8).

为了拓宽卟啉的吸收光谱, 尽可能与太阳光分布相 匹配以提高捕光能力，降低卟啉不对称性和延长共轭体 系是被广泛采纳的两种设计. 降低不对称性是为了使简 并轨道能级裂分, 从而拓宽谱带并提高 $\mathrm{Q}$ 带的吸收强 度 ${ }^{[18,58]}$.

Zn-5 是早期被应用于 DSSCs 的不对称卟啉 ${ }^{[58,59]}$, 它和其他染料类似，在吓啉的一个方向上使用羒基作为 电子注入端与 $\mathrm{TiO}_{2}$ 连接，其他三个方向是三甲基取代 苯基，该基团由于存在很大的空间位阻，可以抑制卟啉 发生堆积. 利用该染料敏化 P-25 $\mathrm{TiO}_{2}$ 纳米颗粒制作光 阳极时可获得 $4.6 \%$ 的光电转换效率，相当于同等条件 下 N719 染料的 $70 \%$. 另外, 采取何种芳环连接受体与 卟啉核对染料性能也将产生不同影响 ${ }^{[58,60]}, \mathrm{Zn}-6$ 和 Zn-7 就可能在 $\mathrm{TiO}_{2}$ 颗粒表面吸附构象不同而导致两者效率 出现差异, Zn-8 分子中也因为噻吩环不能与卟啉核在同 一平面而导致共轭程度差，电子云不能与 $\mathrm{TiO}_{2}$ 导带很 好的交盖, 致使转换效率下降 ${ }^{[60 a]}$.

为了调节卟啉激发电子与 $\mathrm{TiO}_{2}$ 导带的交盖状况, Nazeeruddin 等 ${ }^{[61]}$ 在卟啉 $\beta$ 位连接不同拉电子基团作为 电子注入端，制得染料 Zn-9, 该卟啉能获得转化效率达
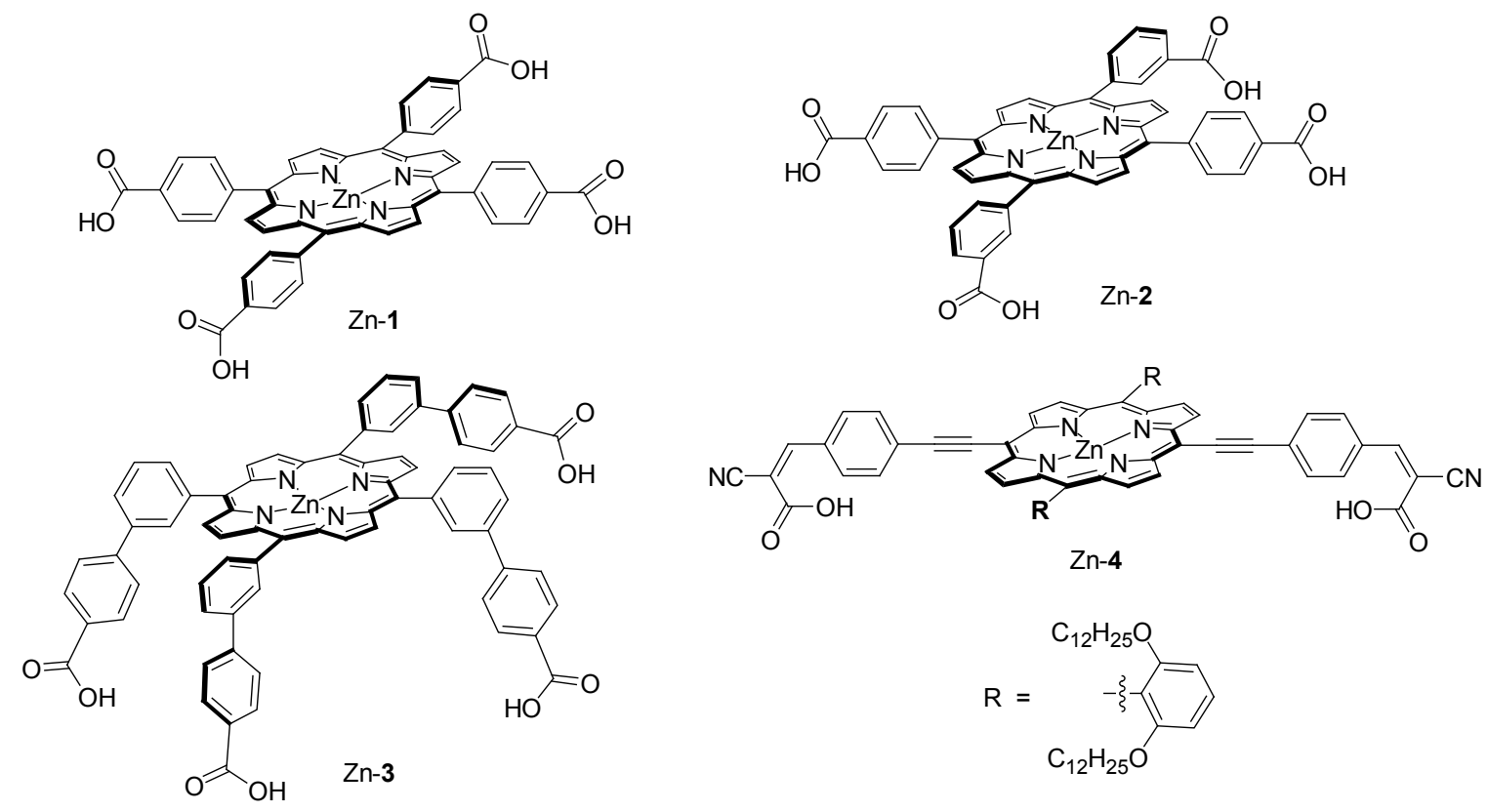

图 8 对称卟啉

Figure 8 Symmetrical porphyrin 

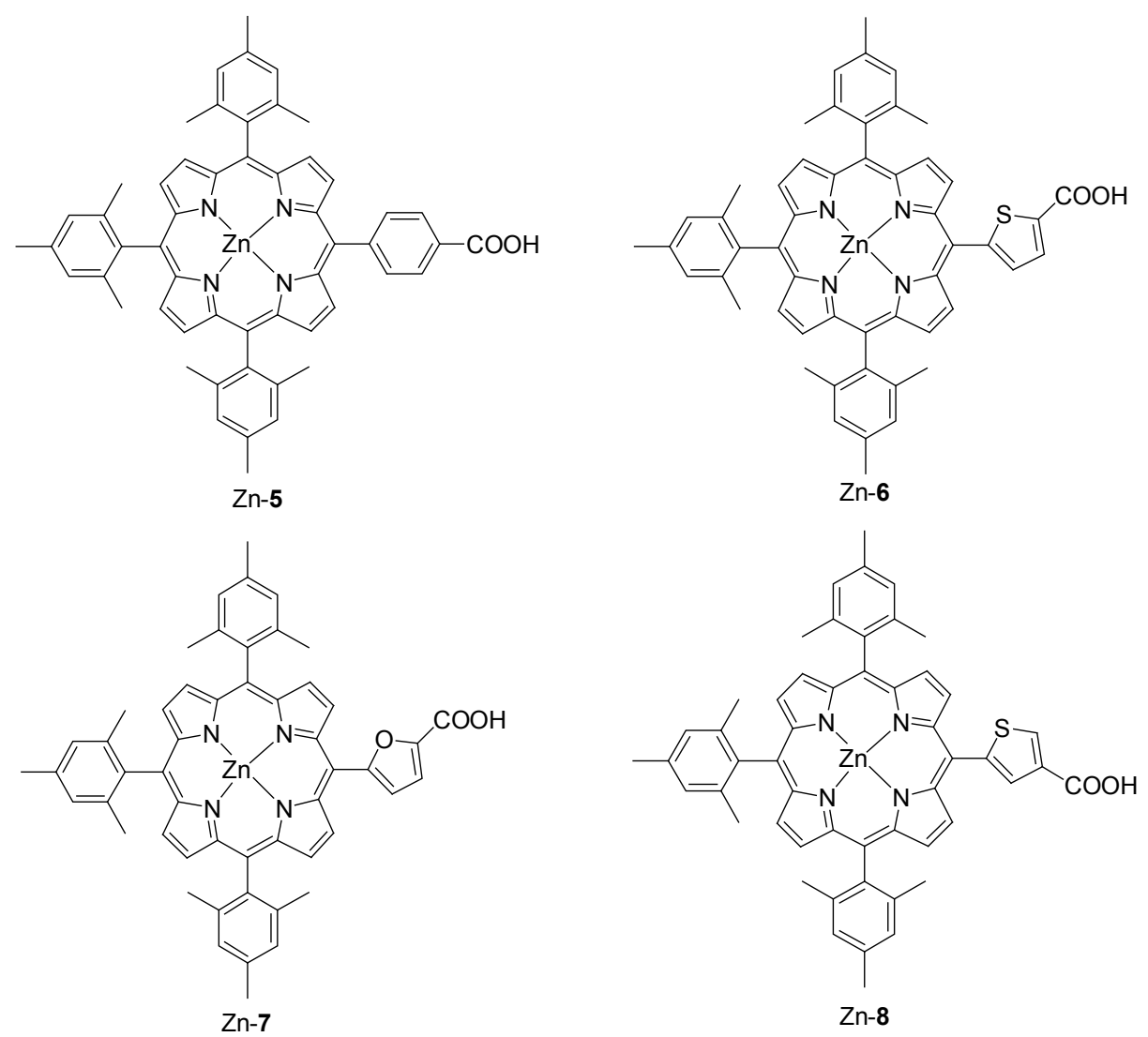

图 9 使用不同芳环连接羧基的不对称卟啉

Figure 9 Unsymmetrical porphyrin with different spacer between the core and carboxyl
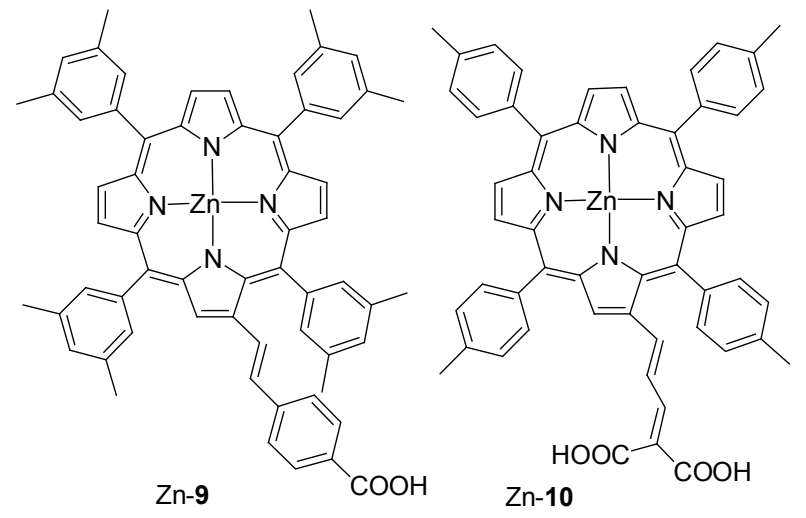

图 $10 \beta$-取代不对称卟啉

Figure $10 \quad \beta$-Substituted unsymmetrical porphyrin

$4.8 \%$ 的光电池, 这开辟了卟啉染料研究的新方向. Grätzel 小组 ${ }^{[22]}$ 和 Officer 的小组 ${ }^{[63]}$ 还进行了在 $\beta$ 位修饰 卟啉的深入研究, 获得了转换效率达 $7.1 \%$ 的卟啉染料

\section{Zn-10.}

相对而言, 在卟啉结构修饰中, 最令人振奋的莫过 于将推拉结构引入卟啉中 ${ }^{[64]}$, 该结构使得卟啉的 Soret 带和 $\mathrm{Q}$ 带都大大拓宽并发生了明显的红移, 这使得光电 流密度大幅提升. 其中 Zn-11 和 Zn-12 在他们的实验条 件下分别获得了 $6.0 \%$ 和 $5.7 \%$ 的转换效率, 这与相同条
件下分别使用 N3 和 N719 染料获得的效率相似. 他们还 发现在不使用散射层时 Zn-12 也不会像 N719 那样效率 迅速下降 ${ }^{[64 c]}$. 最近他们与 Grätzel 的小组合作, 利用 Zn-12 制作 DSSCs, 在进行了器件制作的优化后, 得到 了转换效率高达 $11 \%$ 的光电池, 这也是目前使用非钓染 料制作的最高转化效率的 DSSCs ${ }^{[65]}$.

虽然这实现了卟啉染料转换效率的一次飞跃, 然而 比起钉染料来说, 吓啉染料制作的光电池还存在开路电 压相对较低的问题. 刀维光等 ${ }^{[66]}$ 最近研究发现, 两个叔 丁基或烷氧基团取代在卟啉核两侧苯环的邻位时, 要比 取代在间位或对位时所制得的卟啉氧化还原电位更负, 故能获得更高的开路电压, 如图 12 所示.

\subsection{2 酞菁}

酞菁又叫氮杂卟啉，相对于卟啉而言，目前以它制 作的 DSSC 效率还较低, 一个重要的原因是由于其在 $\mathrm{TiO}_{2}$ 表面强烈的堆积作用, 另外, 激发态缺乏方向性也 是限制其效率提高的一个关键因素. 激发态的方向性即 应使染料的 LUMO 与 Ti 3d 轨道能较好的交盖, 以获得 电子从激发态染料向 $\mathrm{TiO}_{2}$ 导带的顺利转移 ${ }^{[67]}$. 所以最 近在应用于 DSSCs 的酞菁染料的结构修饰研究当中基 本上都针对这两个方面存在的问题进行改善. 


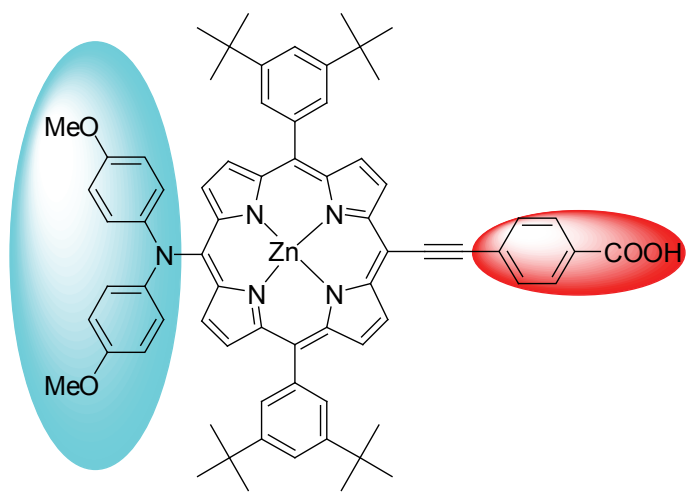

Zn-11

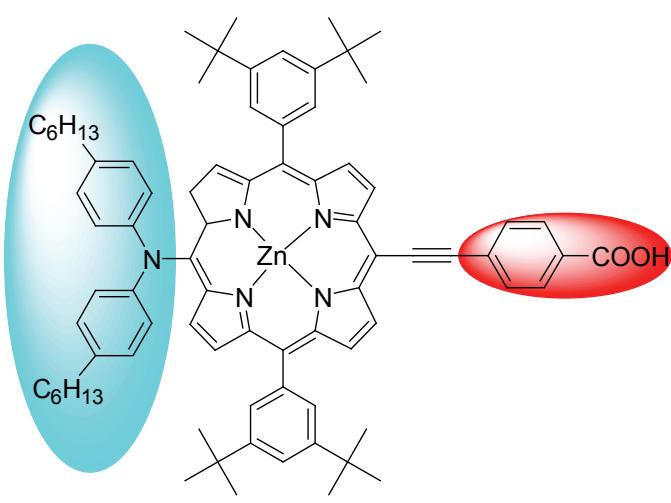

Zn-12

图 11 推拉不对称卟啉

Figure 11 Push-pull unsymmetrical porphyrin

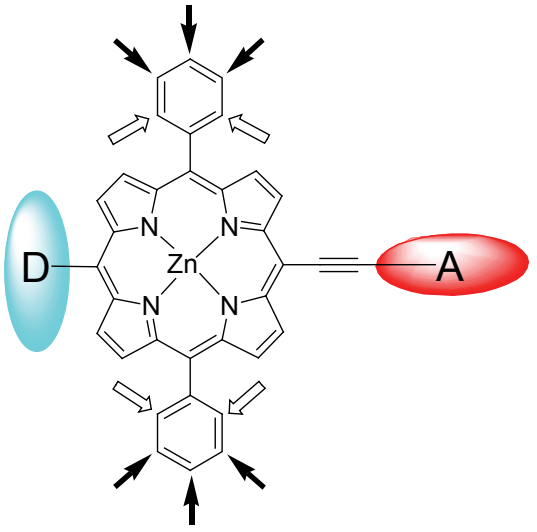

图 12 各种烷氧基取代位置对推拉卟啉开路电压的影响

Figure 12 Good (hollow arrows) and bad (solid arrows) positions of porphyrine for substitution of alkoxyl chains

使用对称酞菁的研究也有报道, 但转换效率普遍很 低. 应用不对称结构的优势在上文已提及, Nazeeruddin 等 ${ }^{[67 a]}$ 在 1999 年首次使用不对称酞菁作为敏化剂制作电 极，后来在 2007 年取得突破，他们合成了不对称酞菁 $\mathrm{Zn}-13$ ，该酞菁含有的三个叔丁基一方面既提高了溶解
性，抑制了堆积的发生，又起到与羒基形成推拉结构的 作用，提高了激发电子的迁移效率. 最终他们以该染料 作为敏化剂获得达 $3.05 \%$ 的光电转换效率 ${ }^{[67 b]}$. 同年 Grätzel 小组又合成了结构类似的酞菁 Zn-14, 将其与鹅 去氧胆酸 $(\mathrm{CDCA})$ 按一定比例共吸附于 $\mathrm{TiO}_{2}$ 纳米颗粒薄 膜后获得高达 $3.52 \%$ 效率的 $\mathrm{DSSCs}^{[68]}$. 毕竟, 叔丁基的 空间位阻有限，并不能完全抑制堆积现象的发生，最近 Mori 等 ${ }^{[69]}$ 引入了更大位阻的基团, 合成了 Zn-15, 研究 发现，该分子几乎完全不能在 $\mathrm{TiO}_{2}$ 表面发生堆积，这使 得效率提高至 $4.6 \%$, 并且是相同实验条件下 N719 的 67\% (图 13).

综上所述，酞菁在 $\mathrm{TiO}_{2}$ 表面的堆积问题已被基本 克服, 然而由于其电子取向性还很差, 其效率提高的空 间依然很大. 类似地将应用于卟啉的推拉结构引入酞 菁, 很可能取得满意的效果, 然而, 不对称酞菁的合成 和纯化难度极高，是一个极具挑战性的工作，有待开发 新型的合成方法来解决这一难题.

另外，在基于酞菁作为敏化剂制作 DSSCs 的研究

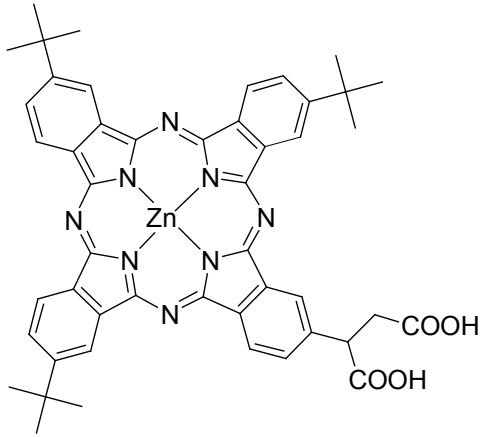

Zn-13

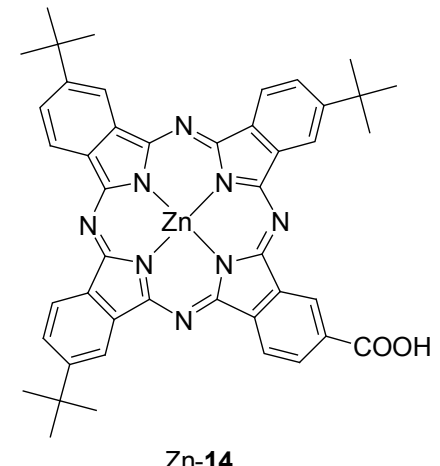

Zn-14

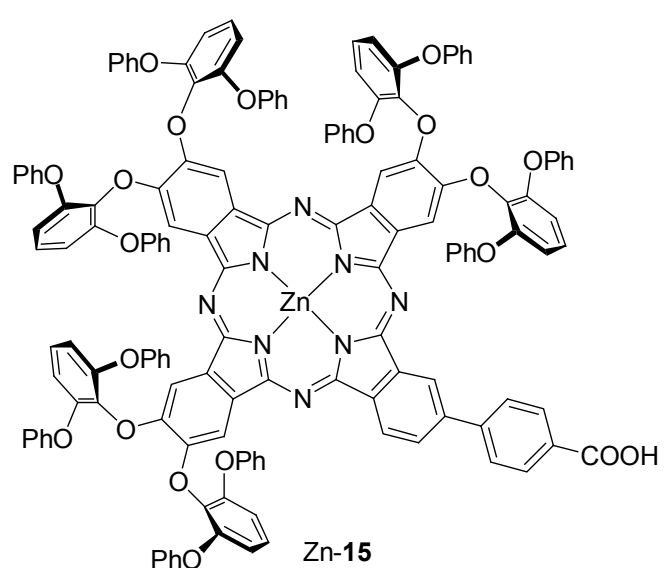

图 13 具有位阻取代基的不对称酞菁

Figure 13 Unsymmetrical phthalocyanine with sterically hindering groups 
中, 非常值得一提的是 McGehee 1 等 ${ }^{[70]}$ 提出的一种新型 DSSCs 器件结构. 该结构是将酞菁吸附在 $\mathrm{TiO}_{2}$ 表面直 接吸收低能量的红光及近红外光而激发, 另外再在电解 质中添加发射光谱尽可能与该酞菁的吸收光谱相重叠 的 “接力染料” (ERD: energy relay dye), ERD 吸收高能 量短波长的光后通过荧光共振转移也能将酞菁激发, 受 激发的酞菁再将电子注入 $\mathrm{TiO}_{2}$ 导带, 这样既拓宽了电 池的光响应范围又避免了使用不同染料共敏化时在 $\mathrm{TiO}_{2}$ 表面可能发生的竞争吸附. 该方法提出了一种解决 $\mathrm{TiO}_{2}$ 颗粒表面积有限, 采用具有互补光谱的染料共敏化 $\mathrm{TiO}_{2}$ 时, 各染料的吸附量可能不足这一问题的新思路.

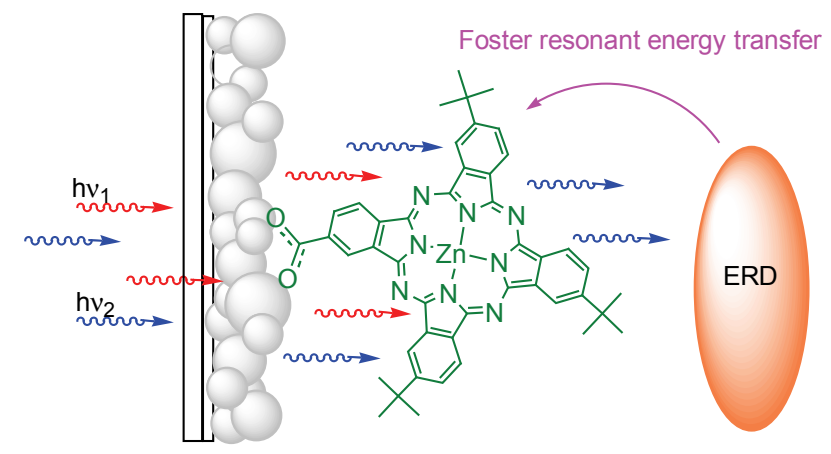

图 14 荧光共振转移在 DSSCs 中的应用

Figure 14 Application of Förster resonant energy transfer in DSSCs

采用该方法使得电池较仅使用的酞菁的电池效率 提高了 $26 \%{ }^{[70]}$, 在固体染料敏化太阳能电池当中, 该方 法也被证明是有效的 ${ }^{[71]}$. 寻找一种发射光谱能与酞菁 吸收光谱最大程度的重叠, 提高荧光共振转移效率是提 高这种新型 DSSCs 效率的关键 ${ }^{[72]}$.

\section{3 结论与展望}

能源危机是目前人类面临的最大挑战之一, 而太阳 能在未来能源结构中必将占据重要地位; 低成本高效率 的太阳能电池是开发利用该清洁能源的关键技术. 具有 低生产成本优势的染料敏化太阳能电池还需要在光电 转换效率上面进一步提升, 而达到该目的的一个重要手 段是开发具有宽光谱响应范围的敏化剂. 目前无论是钉 染料或胺类染料最大吸收光谱普遍集中在 $650 \mathrm{~nm}$ 以下, 怎样将敏化剂光谱向太阳最大光子流所在的红光和近 红外部分拓宽是研究者们还一直努力解决的问题. 另 外, 可供选择的染料种类还非常多, 尝试开发其他类型 的染料将是未来敏化剂研究的重要方向之一. 量子点作 为敏化剂的研究已经取得可喜的进展, 也是目前敏化剂 研究的前沿.

\section{References}

[1] Desilvestro, J.; Grätzel, M.; Kavan, L.; Moser, J.; Augustynski, J. J. Am. Chem. Soc. 1985, 107(10), 2988.

[2] O'Regan, B.; Grätzel, M. Nature 1991, 353(6346), 737.

[3] Chiba, Y.; Islam, A.; Watanabe, Y.; Komiya, R.; Koide, N.; Han, L. Y. Jpn. J. Appl. Phys. 2006, 45(24 28), 638.

[4] Bullis, K. More Efficient, and Cheaper, Solar Cells http://www. technologyreview.com/energy/23459/.

[5] Dye-Sensitized Solar to Go http://www.technologyreview.com/energy/23775/.

[6] Research and Development Aimed at Realizing New Products and Services of the Future http://www.sony.net/SonyInfo/csr/ environment/technology/.

[7] Sundar, N. Dye-sensitized Solar Cells, A Promising New Generation of Solar Cells http://www.exposolar.org/2010/eng/ center $/$ contents.asp?idx $=79 \&$ page $=1 \&$ search $=\&$ searchstring $=$ \&news_type $=\mathrm{C}$.

[8] Wemett, T. Konarka Technologies Becomes First Company in the Americas to Receive EPFL License for Dye-Sensitized Solar Cells http://www.konarka.com/index.php/site/pressreleasedetail/first_co mpany_in_the_americas_to_receive_epfl_license_for_dye_sensitiz ed.

[9] At Solarprint we are developing the World's first High Volume Manufacturing line for a fully DSSCs Printable Solution http:// www.solarprint.ie/our-technology/manufacturing.

[10] Birnie, D. P.; Vijayakumar, V.; Du Pasquier, A. Sol. Energy Mater. Sol. Cells 2011, 95(8), 2120.

[11] Komg, F.-T.; Dai, S.-Y.; Wang, K.-J. Chem. Online 2005, 5, 338 (in Chinese).

(孔凡太, 戴松元, 王孔嘉, 化学通报, 2005, 5, 338.)

[12] Liang, M.; Tao, Z.-J.; Chen, J. Chem. Online 2005, 12, 889 (in Chinese).

(梁茂, 陶占良, 陈军, 化学通报, 2005, 12, 889.)

[13] Zhou, D.; She, X.-L.; Song, G.-J. Precious Metals 2010, 31(1), 37 (in Chinese).

(周迪, 余希林, 宋国君, 贵金属, 2010, 31(1), 37.)

[14] Wu, D.; Shen, Z.; Xue, Z.-L.; You, X.-Z. Chin. J. Inorg. Chem. 2007, 23(1), 1 (in Chinese).

(吴迪, 沈珍, 薛兆历, 游效曾, 无机化学学报, 2007, 23(1), 1.)

[15] Qin, G.-X.; Yuan, X.-M.; Li, X.-F. J. Chaohu College 2009, 11(38), 9 (in Chinese).

(秦国旭; 袁希梅; 李祥飞，巢湖学院学报, 2009, 11(38), 9.)

[16] Gratzel, M. Acc. Chem. Res. 2009, 42(11), 1788.

[17] (a) O'Regan, B. C.; Lopez-Duarte, I.; Martinez-Diaz, M. V.; Forneli, A.; Albero, J.; Morandeira, A.; Palomares, E.; Torres, T.; Durrant, J. R. J. Am. Chem. Soc. 2008, 130(10), 2906.

(b) O'Regan, B. C.; Walley, K.; Juozapavicius, M.; Anderson, A.; Matar, F.; Ghaddar, T.; Zakeeruddin, S. M.; Klein, C.; Durrant, J. R. J. Am. Chem. Soc. 2009, 131(10), 3541.

[18] Imahori, H.; Umeyama, T.; Ito, S. Acc. Chem. Res. 2009, 42(11), 1809.

[19] Sun, S. R.; Gao, L.; Liu, Y. Q. Appl. Phys. Lett. 2010, 96(8).

[20] Mishra, A.; Fischer, M. K. R.; Bauerle, P. Angew. Chem., Int. Ed. 2009, 48(14), 2474.

[21] Nazeeruddin, M. K.; Pechy, P.; Renouard, T.; Zakeeruddin, S. M.; Humphry-Baker, R.; Comte, P.; Liska, P.; Cevey, L.; Costa, E.; Shklover, V.; Spiccia, L.; Deacon, G. B.; Bignozzi, C. A.; Gratzel, M. J. Am. Chem. Soc. 2001, 123(8), 1613.

[22] (a) Chen, C. Y.; Lu, H. C.; Wu, C. G.; Chen, J. G.; Ho, K. C. $A d v$. Funct. Mater. 2007, 17(1), 29.

(b) Chen, C. Y.; Wu, S. J.; Li, J. Y.; Wu, C. G.; Chen, J. G.; Ho, K. 
C. Adv. Mater. 2007, 19(22), 3888 .

(c) Chen, C. Y.; Wu, S. J.; Wu, C. G.; Chen, J. G.; Ho, K. C. Angew. Chem., Int. Ed. 2006, 45(35), 5822.

[23] Wang, M. K.; Moon, S. J.; Zhou, D. F.; Le Formal, F.; Cevey-Ha, N. L.; Humphry-Baker, R.; Gratzel, C.; Wang, P.; Zakeeruddin, S. M.; Gratzel, M. Adv. Funct. Mater. 2010, 20(11), 1821.

[24] Wu, K. L.; Hsu, H. C.; Chen, K.; Chi, Y.; Chung, M. W.; Liu, W. H.; Chou, P. T. Chem. Commun. 2010, 46(28), 5124.

[25] (a) Klein, C.; Nazeeruddin, M. K.; Liska, P.; Di Censo, D.; Hirata, N.; Palomares, E.; Durrant, J. R.; Gratzel, M. Inorg. Chem. 2005, 44(2), 178.

(b) Nazeeruddin, M. K.; Klein, C.; Liska, P.; Gratzel, M. Coord. Chem. Rev. 2005, 249(13 14), 1460.

[26] Wang, P.; Zakeeruddin, S. M.; Moser, J. E.; Nazeeruddin, M. K.; Sekiguchi, T.; Gratzel, M. Nat. Mater. 2003, 2(7), 498.

[27] Hirata, N.; Lagref, J. J.; Palomares, E. J.; Durrant, J. R.; Nazeeruddin, M. K.; Gratzel, M.; Di Censo, D. Chem.-Eur. J. 2004, 10(3), 595.

[28] Fan, S. H.; Zhang, A. G.; Ju, C. C.; Gao, L. H.; Wang, K. Z. Inorg. Chem. 2010, 49(8), 3752.

[29] Willinger, K.; Fischer, K.; Kisselev, R.; Thelakkat, M. J. Mater. Chem. 2009, 19(30), 5364.

[30] Kui, S. C. F.; Sham, I. H. T.; Cheung, C. C. C.; Ma, C. W.; Yan, B. P.; Zhu, N. Y.; Che, C. M.; Fu, W. F. Chem.-Eur. J. 2007, 13(2), 417.

[31] Wadman, S. H.; Kroon, J. M.; Bakker, K.; Lutz, M.; Spek, A. L.; van Klink, G. P. M.; van Koten, G. Chem. Commun. 2007, (19), 1907.

[32] Bessho, T.; Yoneda, E.; Yum, J. H.; Guglielmi, M.; Tavernelli, I.; Imai, H.; Rothlisberger, U.; Nazeeruddin, M. K.; Gratzel, M. J. Am. Chem. Soc. 2009, 131(16), 5930.

[33] Chang, W.-C.; Chen, H.-S.; Li, T.-Y.; Hsu, N.-M.; Tingare, Y. S.; Li, C.-Y.; Liu, Y.-C.; Su, C.; Li, W.-R. Angew. Chem., Int. Ed. 2010, 49(44), 8161.

[34] Rehm, J. M.; McLendon, G. L.; Nagasawa, Y.; Yoshihara, K.; Moser, J.; Grätzel, M. J. Phys. Chem. 1996, 100(23), 9577.

[35] Hara, K.; Sayama, K.; Ohga, Y.; Shinpo, A.; Suga, S.; Arakawa, H. Chem. Commun. 2001, (6), 569.

[36] Hara, K.; Kurashige, M.; Ito, S.; Shinpo, A.; Suga, S.; Sayama, K.; Arakawa, H. Chem. Commun. 2003, (2), 252.

[37] (a) Hagberg, D. P.; Edvinsson, T.; Marinado, T.; Boschloo, G.; Hagfeldt, A.; Sun, L. C. Chem. Commun. 2006, (21), 2245.

(b) Hagberg, D. P.; Yum, J. H.; Lee, H.; De Angelis, F.; Marinado, T.; Karlsson, K. M.; Humphry-Baker, R.; Sun, L. C.; Hagfeldt, A.; Gratzel, M.; Nazeeruddin, M. K. J. Am. Chem. Soc. 2008, 130(19), 6259.

[38] (a) Li, G.; Jiang, K. J.; Li, Y. F.; Li, S. L.; Yang, L. M. J. Phys. Chem. C 2008, 112(30), 11591.

(b) Thomas, K. R. J.; Hsu, Y. C.; Lin, J. T.; Lee, K. M.; Ho, K. C.; Lai, C. H.; Cheng, Y. M.; Chou, P. T. Chem. Mater. 2008, 20(5), 1830 .

[39] (a) Hagberg, D. P.; Marinado, T.; Karlsson, K. M.; Nonomura, K.; Qin, P.; Boschloo, G.; Brinck, T.; Hagfeldt, A.; Sun, L. J. Org. Chem. 2007, 72(25), 9550 .

(b) Liu, W. H.; Wu, I. C.; Lai, C. H.; Lai, C. H.; Chou, P. T.; Li, Y. T.; Chen, C. L.; Hsu, Y. Y.; Chi, Y. Chem. Commun. 2008, (41), 5152 .

[40] Kim, C.; Choi, H.; Kim, S.; Baik, C.; Song, K.; Kang, M. S.; Kang, S. O.; Ko, J. J. Org. Chem. 2008, 73(18), 7072.

[41] Xu, W.; Peng, B.; Chen, J.; Liang, M.; Cai, F. J. Phys. Chem. C 2008, 112(3), 874 .

[42] Choi, H.; Raabe, I.; Kim, D.; Teocoli, F.; Kim, C.; Song, K.; Yum,
J. H.; Ko, J.; Nazeeruddin, M. K.; Gratzel, M. Chem.-Eur. J. 2010 , 16(4), 1193

[43] (a) Kim, S.; Choi, H.; Kim, D.; Song, K.; Kang, S. O.; Ko, J. Tetrahedron 2007, 63(37), 9206.

(b) Kim, S.; Lee, J. K.; Kang, S. O.; Ko, J.; Yum, J. H.; Fantacci, S.; De Angelis, F.; Di Censo, D.; Nazeeruddin, M. K.; Gratzel, M. J. Am. Chem. Soc. 2006, 128(51), 16701.

[44] Choi, H.; Lee, J. K.; Song, K.; Kang, S. O.; Ko, J. Tetrahedron 2007, 63(15), 3115.

[45] Kim, D.; Lee, J. K.; Kang, S. O.; Ko, J. Tetrahedron 2007, 63(9), 1913.

[46] Wang, Z. S.; Koumura, N.; Cui, Y.; Takahashi, M.; Sekiguchi, H.; Mori, A.; Kubo, T.; Furube, A.; Hara, K. Chem. Mater. 2008 , 20(12), 3993.

[47] Chen, C. H.; Hsu, Y. C.; Chou, H. H.; Thomas, K. R. J.; Lin, J. T.; Hsu, C. P. Chem.-Eur. J. 2010, 16(10), 3184.

[48] Zhang, G. L.; Bala, H.; Cheng, Y. M.; Shi, D.; Lv, X. J.; Yu, Q. J.; Wang, P. Chem. Commun. 2009, (16), 2198.

[49] Zhang, G.; Bala, H.; Cheng, Y.; Shi, D.; Lv, X.; Yu, Q.; Wang, P. Chem. Commun. 2009, (16), 2198.

[50] Liang, Y. L.; Peng, B.; Liang, J.; Tao, Z. L.; Chen, J. Org. Lett. 2010, 12(6), 1204.

[51] Wenger, S.; Bouit, P. A.; Chen, Q. L.; Teuscher, J.; Di Censo, D.; Humphry-Baker, R.; Moser, J. E.; Delgado, J. L.; Martin, N.; Zakeeruddin, S. M.; Grazel, M. J. Am. Chem. Soc. 2010, 132(14), 5164.

[52] Zeng, W. D.; Cao, Y. M.; Bai, Y.; Wang, Y. H.; Shi, Y. S.; Zhang, M.; Wang, F. F.; Pan, C. Y.; Wang, P. Chem. Mater. 2010, 22(5), 1915.

[53] Wang, P.; Cai, N. C., N.; Moon, S. J.; Cevey-Ha, L.; Moehl, T.; Humphry-Baker, R.; Zakeeruddin, S. M.; Gratzel, M. Nano Lett. 2011, 11(4), 1452.

[54] Fischer, M. K. R.; Wenger, S.; Wang, M. K.; Mishra, A.; Zakeeruddin, S. M.; Grätzel, M.; Bauerle, P. Chem. Mater. 2010, 22(5), 1836.

[55] Kay, A.; Grätzel, M. J. Phys. Chem. 1993, 97(23), 6272.

[56] (a) Cherian, S.; Wamser, C. C. J. Phys. Chem. B 2000, 104(15), 3624 .

(b) Rochford, J.; Chu, D.; Hagfeldt, A.; Galoppini, E. J. Am. Chem. Soc. 2007, 129(15), 4655.

[57] Lee, C. Y.; She, C. X.; Jeong, N. C.; Hupp, J. T. Chem. Commun. 2010, 46(33), 6090.

[58] Hayashi, S.; Tanaka, M.; Hayashi, H.; Eu, S.; Umeyama, T.; Matano, Y.; Araki, Y.; Imahori, H. J. Phys. Chem. C 2008, 112(39), 15576 .

[59] Watson, D. F.; Marton, A.; Stux, A. M.; Meyer, G. J. J. Phys. Chem. B 2004, 108(31), 11680

[60] (a) Eu, S.; Hayashi, S.; Umeyama, T.; Oguro, A.; Kawasaki, M.; Kadota, N.; Matano, Y.; Imahori, H. J. Phys. Chem. C 2007, $111(8), 3528$.

(b) Eu, S.; Hayashi, S.; Urneyama, T.; Matano, Y.; Araki, Y.; Imahori, H. J. Phys. Chem. C 2008, 112(11), 4396.

(c) Kira, A.; Matsubara, Y.; Iijima, H.; Umeyama, T.; Matano, Y.; Ito, S.; Niemi, M.; Tkachenko, N. V.; Lemmetyinen, H.; Imahori, H. J. Phys. Chem. C 2010, 114(25), 11293.

[61] Nazeeruddin, M. K.; Humphry-Baker, R.; Officer, D. L.; Campbell, W. M.; Burrell, A. K.; Gratzel, M. Langmuir 2004, $20(15), 6514$.

[62] Schmidt-Mende, L.; Campbell, W. M.; Wang, Q.; Jolley, K. W.; Officer, D. L.; Nazeeruddin, M. K.; Gratzel, M. ChemPhysChem 2005, 6(7), 1253

[63] Campbell, W. M.; Jolley, K. W.; Wagner, P.; Wagner, K.; Walsh, P. J.; Gordon, K. C.; Schmidt-Mende, L.; Nazeeruddin, M. K.; 
Wang, Q.; Gratzel, M.; Officer, D. L. J. Phys. Chem. C 2007, $111(32), 11760$

[64] (a) Hsieh, C. P.; Lu, H. P.; Chiu, C. L.; Lee, C. W.; Chuang, S. H.; Mai, C. L.; Yen, W. N.; Hsu, S. J.; Diau, E. W. G.; Yeh, C. Y. J. Mater. Chem. 2010, 20(6), 1127.

(b) Lee, C. W.; Lu, H. P.; Lan, C. M.; Huang, Y. L.; Liang, Y. R.; Yen, W. N.; Liu, Y. C.; Lin, Y. S.; Diau, E. W. G.; Yeh, C. Y. Chem.-Eur. J. 2009, 15(6), 1403

(c) Lu, H. P.; Tsai, C. Y.; Yen, W. N.; Hsieh, C. P.; Lee, C. W.; Yeh, C. Y.; Diau, E. W. G. J. Phys. Chem. C 2009, 113(49), 20990.

[65] Bessho, T.; Zakeeruddin, S. M.; Yeh, C. Y.; Diau, E. W. G.; Gratzel, M. Angew. Chem., Int. Ed. 2010, 49(37), 6646.

[66] Lin, C. Y.; Chang, Y. C.; Wang, C. L.; Pan, T. Y.; Hong, S. H.; Lan, C. M.; Kuo, H. H.; Lo, C. F.; Hsu, H. Y.; Diau, E. W. G. Chem. Commun. 2011, 47(31), 8910.

[67] (a) Nazeeruddin, M. K.; Humphry-Baker, R.; Gratzel, M.; Wohrle, D.; Schnurpfeil, G.; Schneider, G.; Hirth, A.; Trombach, N. $J$. Porphyrins Phthalocyanines 1999, 3(3), 230. (b) Reddy, P. Y.; Giribabu, L.; Lyness, C.; Snaith, H. J.; Vijaykumar, C.; Chandrasekharam, M.; Lakshmikantam, M.; Yum, J. H.; Kalyanasundaram, K.; Graetzel, M.; Nazeeruddin, M. K. Angew. Chem., Int. Ed. 2007, 46(3), 373.

[68] Cid, J. J.; Yum, J. H.; Jang, S. R.; Nazeeruddin, M. K.; Ferrero, E. M.; Palomares, E.; Ko, J.; Gratzel, M.; Torres, T. Angew. Chem., Int. Ed. 2007, 46(44), 8358.

[69] Mori, S.; Nagata, M.; Nakahata, Y.; Yasuta, K.; Goto, R.; Kimura, M.; Taya, M. J. Am. Chem. Soc. 2010, 132(12), 4054.

[70] Hardin, B. E.; Hoke, E. T.; Armstrong, P. B.; Yum, J. H.; Comte, P.; Torres, T.; Frechet, J. M. J.; Nazeeruddin, M. K.; Gratzel, M.; McGehee, M. D. Nat. Photonics 2009, 3(7), 406.

[71] Yum, J. H.; Hardin, B. E.; Moon, S. J.; Baranoff, E.; Nuesch, F.; McGehee, M. D.; Gratzel, M.; Nazeeruddin, M. K. Angew. Chem., Int. Ed. 2009, 48(49), 9277.

[72] Hardin, B. E.; Yum, J. H.; Hoke, E. T.; Jun, Y. C.; Pechy, P.; Torres, T.; Brongersma, M. L.; Nazeeruddin, M. K.; Gratzel, M.; McGehee, M. D. Nano Lett. 2010, 10(8), 3077.

(Cheng, F.; Li, L.) 